\title{
A screening programme for the prospective prevention of Mediterranean anaemia in Latium: results of seven years' work
}

\author{
I BIANCO, B GRAZIANI, M LERONE, P CONGEDO, D PONZINI, \\ F BRACONI, ANDC ALIQUO \\ From the Associazione Nazionale per la Lotta contro le Microcitemie in Italia, Centro di Studi \\ della Microcitemia di Roma, Rome. Italy.
}

SUmmary Since 1975 the Rome Microcythaemia Centre has carried out every year, under the auspices of the health authorities of the Latium region, a screening of thalassaemics among intermediate schoolchildren of Latium. From these campaigns, knowledge about thalassaemias among the young adult population has grown which, in its turn, has resulted in screening of these young adults.

Through screening in schools between 1975 and 1982, of 289763 students examined, 6838 thalassaemics were identified, 6045 of whom were $\beta$ - or $\delta$-thalassaemics. The total number of young thalassaemics who are identified at present in the Centre through screenings of schoolchildren and young adults is about 3300 per year. Furthermore, from January 1980 to April 1983, 110 prospective couples of child-bearing age at risk ( 94 of whom originated from Latium) were identified at the Centre, and five homozygous fetuses (three of which originated from Latium) were diagnosed.

These data derive from an area in which the frequency of thalassaemia is only $2.4 \%$, and they show that the programme in Latium for the prevention of Mediterranean anaemia has been successful.

The screening of heterozygous thalassaemia carriers among intermediate school students ( 13 to 14 years old) started in 1975 in Latium, was continued under the auspices of the regional health authorities, and is now on a very large scale. During the last few years further publicity in the adult population, together with the schools screening, stimulated the carrying out of a second screening of young adults which has also now reached large dimensions.

Following our two previous papers published in this Journal, ${ }^{12}$ we present all the results of the first seven years' work.

\section{Methods}

SCREENING IN SCHOOLS

The screening and laboratory methods for the diagnosis of thalassaemia have remained the same

Received for publication I9 November 198.3 Accepted for publication 28 December 1983 as in the first years. ${ }^{1-3}$ They are shown in table 1 and fig 1 .

\section{APPROACHES TO THE YOUNG}

ADULT POPULATION

In 1982 the Centre started a new approach to the young adult population using for publicity the Local Health Units, resulting from the recent reform of the health services, and marriage registry offices. Information is disseminated through direct approaches to the public and free distribution of pamphlets and booklets. Subjects requesting examination for thalassaemia as a consequence of this information are studied with the full diagnostic procedure (steps 1 and 2, fig 1 ) in the Centre.

IABLE 1 Obligatory stages in the schools screening.

(1) Educational programme in the schools.

(2) Collecting of blood samples from the students and analyses in the laboratories.

(3) Communication of the results to thalassaemic and non-thalassaemic students. Examination of thalassaemic families and genetic counselling. 


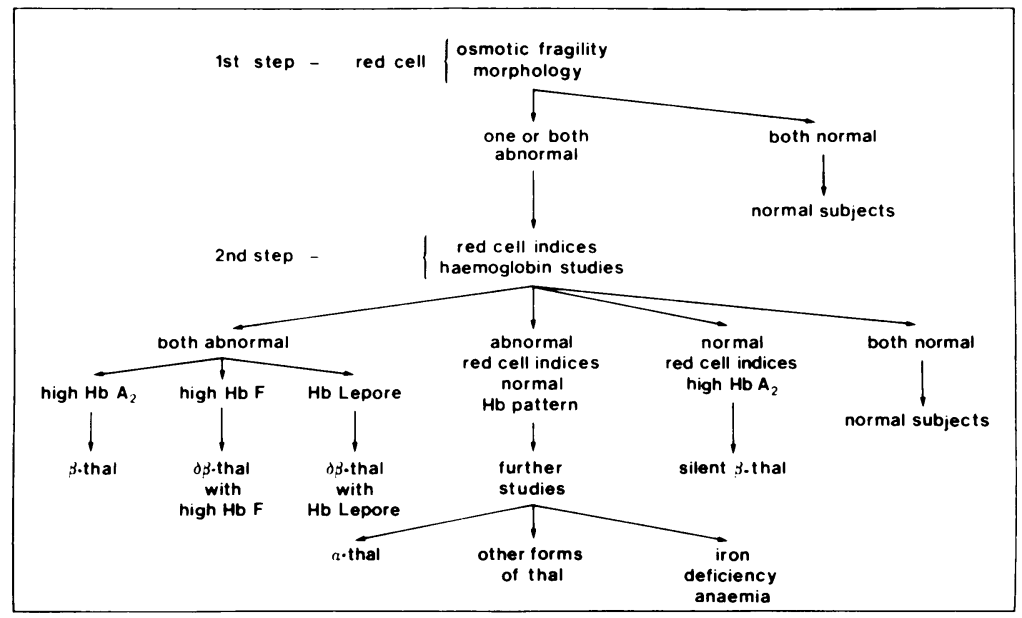

FIG 1 Flow chart of the diag. nostic analyses for the mass screening for thalassaemia.

\section{Results}

The schools screening attained its present state from the fourth year onwards. After the initial explorations, the internal and mountainous areas of Rieti, Rome, and Frosinone provinces (where the frequency of thalassaemia is about $1 \%$ ) were excluded from the screening. However, the remaining areas of Latium which contained the most affected were fully screened, and the highest rates of information and examination of students were those of the province of Latina (table 2), where the incidence of thal-

TABLE 2 Percentage of schoolchildren informed and examined in the last four mass screenings in the provinces of Latium.

\begin{tabular}{llll}
\hline Province & $\begin{array}{l}\text { No informed } \\
\text { No enrolled } \\
(\%)\end{array}$ & $\begin{array}{l}\text { No examined } \\
\text { No informed } \\
(\%)\end{array}$ & $\begin{array}{l}\text { No examined } \\
\text { No enrolled } \\
(\%)\end{array}$ \\
\hline Rome & $90 \cdot 5$ & $78 \cdot 7$ & $71 \cdot 3$ \\
Frosinone & $58 \cdot 5$ & $82 \cdot 7$ & $48 \cdot 4$ \\
Latina & $90 \cdot 8$ & $81 \cdot 9$ & $74 \cdot 3$ \\
Viterbo & 73.4 & $84 \cdot 2$ & $61 \cdot 8$ \\
\hline
\end{tabular}

assaemia $(2.80 \%)$ is the highest of the Latium provinces (table 3 , fig 2 ).

In the course of the first seven campaigns 289763 students were examined, and 6838 thalassaemics identified, 6045 of whom are $\beta$ - or $\delta \beta$-thalassaemia carriers.

The screening programme was favourably accepted by the population from its inception. Thalassaemic families agreed to be examined in the Centre without any prejudice or anxiety.

After only 2 to 3 years from the start of the schools screening, and therefore before the screening had been extended to young adults, the whole population quickly became aware of the thalassaemia programme due to the effect of the schools screenings.

This publicity, in turn, produced a rapid rise in the number of people willing to be examined in the Centre (fig 3), which has increased from a few a day in 1976 to 70 to 80 in 1982. Thus, a second screening of the young adult population of child-bearing age started, which includes at present nearly 15000

TABLE 3 Results of 7 years of screening for thalassaemia in intermediate schools of Latium.

\begin{tabular}{|c|c|c|c|c|c|c|c|c|c|}
\hline \multirow[t]{2}{*}{ Provinces of Latium } & \multirow[t]{2}{*}{ No tested } & \multicolumn{4}{|c|}{ No of thalassaemics } & \multirow{2}{*}{$\begin{array}{l}\text { Total } \\
\text { thalassaemia }\end{array}$} & \multirow{2}{*}{$\begin{array}{l}\% \\
\text { thalassaemia } \\
(S E)\end{array}$} & \multirow{2}{*}{$\begin{array}{l}\text { Total } \\
\text { non- } \alpha\end{array}$} & \multirow{2}{*}{$\begin{array}{l}\% \\
n o n-\alpha \\
(S E)\end{array}$} \\
\hline & & $\beta$ & $\delta \beta$ & Lepore & $\alpha$ & & & & \\
\hline Rome & 219272 & 4479 & 34 & 56 & 587 & 5156 & $2 \cdot 35 \pm 0.03$ & 4569 & $2.08 \pm 0.03$ \\
\hline Latina & 32194 & 763 & 3 & 13 & 123 & 902 & $2 \cdot 80 \div 0 \cdot 09$ & 779 & $2.42 \pm 0.08$ \\
\hline Viterbo & 15354 & 291 & 1 & 2 & 40 & 334 & $2 \cdot 17 \doteqdot 0 \cdot 12$ & 294 & $1 \cdot 91 \pm 0 \cdot 11$ \\
\hline Frosinone & 20222 & 373 & 1 & 4 & 34 & 412 & $2 \cdot 04 \pm 0 \cdot 10$ & 378 & $1 \cdot 87 \pm 0 \cdot 10$ \\
\hline Rieti & 2721 & 25 & & & 9 & 34 & $1 \cdot 25 \pm 0 \cdot 21$ & 25 & $0.92 \div 0.18$ \\
\hline Total & 289763 & $\begin{array}{l}5931 \\
(86 \cdot 7 \%\end{array}$ & $\begin{array}{l}39 \\
(0.6 \%)\end{array}$ & $\begin{array}{l}75 \\
(1 \cdot 1 \%)\end{array}$ & $\begin{array}{l}793 \\
(11.6 \%)\end{array}$ & 6838 & $2 \cdot 36 \pm 0.03$ & 6045 & $2.08 \pm 0.03$ \\
\hline
\end{tabular}




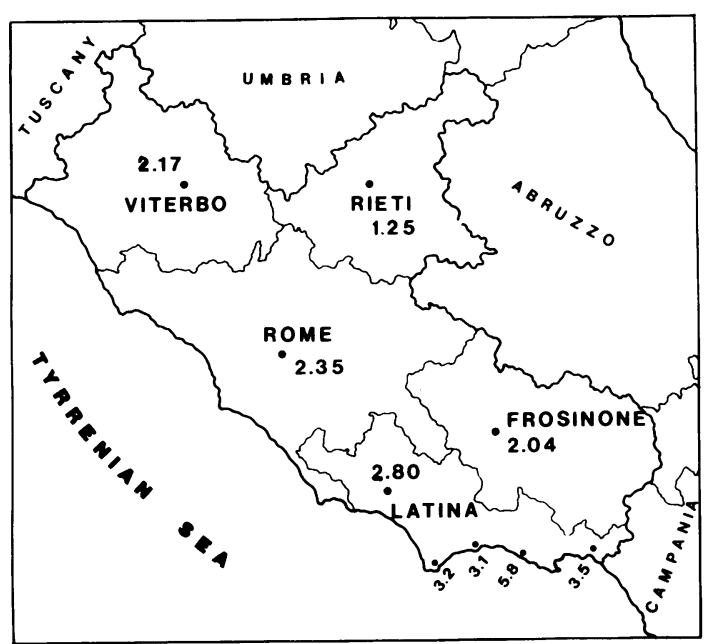

FIG 2 The frequency of thalassaemia in the provinces of Latium.

subjects a year. The pooled yield of young thalassaemics identified per year in the Centre through both screenings is now about 3300 .

Finally, another outcome of the screening is the identification of couples at risk of child-bearing age, which has taken place since 1980 . Some of these couples (51 out of 161) had already had an affected child (retrospective couples) and came to the Centre during or before a new pregnancy (table 4), but the majority (110 out of 161) had no affected children (prospective couples) and came for advice at the Centre before conceiving a child, as a direct or indirect consequence of the schools screening. Of the 94 prospective couples of Latial extraction, 35 (more than a third) were the same students idenfied in the schools screening or through one of their close relatives.
From January 1980 to April 1983, 37 of the 110 prospective couples became pregnant and six of 31 monitored pregnancies (four of which came from Latium) had a homozygous fetus which was aborted.

\section{Discussion}

The results of 7 years' work clearly show that mass screening of a young population is feasible and, above all, that it is possible to reach the final target of prospective prevention of Mediterranean anaemia. The most important data supporting this forecast are the following.

In a vast region of $17000 \mathrm{~km}^{2}$, a single Centre for thalassaemia is able to examine an average of 50000 students per year, which is approximately $80 \%$ of all intermediate school students, and in 7 years it has examined 289763 subjects.

In the same region (which has an average frequency of $\beta$-thalassaemia of $2.1 \%$ ) the Centre identifies every year, in schools and within its catchment area, a total of about 3300 young thalassaemics and 40 prospective couples at risk. These figures show that if the screenings are continued in the future at the same rate, the goal of identifying nearly all the young thalassaemics and all the couples at risk in Latium should be attained in about 15 years. In fact, it can be calculated that there are about 80000 young couples of child-bearing age at risk in Latium (that is, half of the 160000 living in the region) and approximately 350000 older adult couples at risk, that is $(0 \cdot 021)^{2} \cdot 10^{-4} \times 8 \cdot 10^{5}$. If 40 couples at risk continue to be found every year, that will mean that 20 new couples (a reasonable yearly rate of substitution of the total 350 couples) and 20 couples out of those already screened will be discovered every year. Therefore, after 15 to 20 years the 'arrears' will

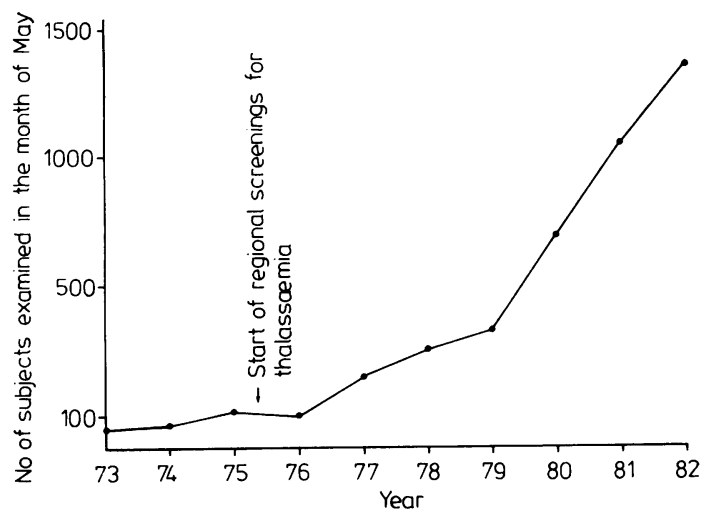

FIG 3 The rate of requested examinations for thalassaemia in the outpatient service of the Centre. Note the sudden increase in the number of examinations from 1977 onwards (2 years after the start of the screenings) and its further dramatic increase since 1979. 
BLE 4 Results of retrospective and prospective prevention of Mediterranean anaemia achieved by the Centre from nuary 1980 to April 1983.

\begin{tabular}{|c|c|c|c|}
\hline & Latium & Other regions & Total \\
\hline \multicolumn{4}{|l|}{ trospective prevention } \\
\hline Vo of couples & 30 & 21 & 51 \\
\hline No of monitored pregnancies & 9 & 4 & 13 \\
\hline \multicolumn{4}{|l|}{ No of interrupted pregnancies with no } \\
\hline fetal exploration & 2 & & 2 \\
\hline No of $\beta$-thalassaemia homozygous fetuses & $\begin{array}{l}1 \\
\text { (expected } 2 \cdot 25)\end{array}$ & $\begin{array}{l}3 \\
\text { (expected } 1 \cdot 00)\end{array}$ & $\begin{array}{l}4 \\
(\text { expected } 3 \cdot 25)\end{array}$ \\
\hline \multicolumn{4}{|l|}{ spective prevention } \\
\hline Vo of couples & $94 *$ & 16 & 110 \\
\hline No of monitored pregnancies & 23 & 8 & 31 \\
\hline \multicolumn{4}{|l|}{ No of interrupted pregnancies with no } \\
\hline fetal exploration & 2 & & 2 \\
\hline No of advanced unexplored pregnancies & 1 & 1 & 2 \\
\hline Antenatal diagnosis refused & $1 \dagger$ & & $\overline{1}$ \\
\hline Vo of fetal losses after exploration & $1+$ & & 1 \\
\hline No of $\beta$-thalassaemia homozygous fetuses & $\begin{array}{l}4 \\
\text { (expected } 5 \cdot 75)\end{array}$ & $\begin{array}{l}2 \\
(\text { expected } 2 \cdot 00)\end{array}$ & $\begin{array}{l}6 \\
(\text { expected } 7 \cdot 75)\end{array}$ \\
\hline
\end{tabular}

134 of these 94 couples at least one of the partners was either the identified student him/herself or a close relative.

ne couple had two pregnancies. The first terminated after the exploration (healthy fetus). At the onset of the second both partners were gnosed as "normal' by another laboratory, the pregnancy was not monitored, and an affected child was born.

ive been caught up and thereafter only the 20 new ospective couples will be identified every year.

A plan for the prevention of Mediterranean Iaemia, similar to the one carried out in Latium, suld therefore appear to be useful for other alassaemic areas, because it is easy, quick, and eap $^{3}$ and yields many positive results.

Modifications might be necessary in individual eas with respect to local situations, but schools reening should always be included in the proamme as this has proved to be a very useful means efficient and permanent dispersal of information the population. The intermediate school proved be the ideal level for screening due to the age of e students (13 to 14 years), an age at which students $\mathrm{n}$ understand and remember the information 1 thalassaemia and, above all, choose either sst-conceptional or preconceptional means of evention.
The authors wish to thank the health authorities of the Latium region for financial support, the school directors and teachers, and in particular the many school doctors and other health workers for their valuable collaboration.

\section{References}

1 Silvestroni E, Bianco I, Graziani B, Carboni C, D’Arca SU. First premarital screening of thalassaemia carriers in intermediate schools in Latium. J Med Genet 1978;15: 202-7.

2 Silvestroni E, Bianco I, Graziani B, et al. Screening of thalassaemia in intermediate schools in Latium: results of four years' work. J Med Genet 1980;17:161-4.

${ }^{3}$ Silvestroni E, Bianco I. A highly cost effective method of mass screening for thalassaemia. $\mathrm{Br} M e d J$ 1983;286: 1007-9.

Correspondence and requests for reprints to Dr I Bianco, Centro di Studi della Microcitemia di Roma, Via Treviso 29, 00161 Rome, Italy. 